\title{
A new method for production of titanium vapor and synthesis of titanium nitride coatings
}

\author{
Sergey N. Grigoriev, Yury A. Melnik, Alexander S. Metel*, and Marina A. Volosova \\ Moscow State University of Technology "STANKIN", 1 Vadkovsky per., Moscow GSP-4 127055, Russian Federation
}

Received: 1 September 2017 / Accepted: 20 November 2017

\begin{abstract}
It is proposed to synthesize on machine parts and cutting tools wear-resistant titanium nitride coatings with the help of the hollow-cathode glow discharge, a molybdenum crucible for titanium evaporation being used as the anode of the discharge and a process vacuum chamber being used as the hollow cathode. The research revealed that at the anode surface area less than a critical value $S^{*}=(2 \mathrm{~m} / \mathrm{M})^{1 / 2} S$, where $S$ is the area of the chamber walls, $m$ is the mass of electrons and $M$ is the mass of ions, the anode fall of potential is positive and grows from $\sim 50 \mathrm{~V}$ at argon pressure $p=0.2 \mathrm{~Pa}$ to $\sim 2 \mathrm{kV}$ at $p=0.02 \mathrm{~Pa}$. At the discharge current $I=0.6 \mathrm{~A}$ electrons accelerated by the anode fall of $0.9 \mathrm{kV}$ transport into the crucible with the inner diameter of $12 \mathrm{~mm}$ the power of $\sim 0.54 \mathrm{~kW}$, which allows the titanium evaporation and the coating deposition rate of $5 \mu \mathrm{m} \cdot \mathrm{h}^{-1}$ on a substrate distanced from the crucible at $100 \mathrm{~mm}$. After the argon is replaced with the nitrogen, titanium nitride coating without titanium droplets is synthesized the deposition rate amounting to about the same value.
\end{abstract}

Keywords: Wear-resistant coatings / titanium evaporation / anode-crucible / electron heating / hollow cathode glow discharge

\section{Introduction}

Wear-resistant TiN coatings substantially increase the useful life of machine parts, tools, and other products, because their hardness of $\sim 25 \mathrm{GPa}$ and more [1] exceeds by many times hardness of the bulk materials. To improve properties of the coatings, they are usually bombarded during the coating synthesis by energetic particles accelerated from the gas discharge plasma [2] or using beam sources [3].

One of the methods widely used for the production of titanium vapor needed for synthesis of the above hard coatings is vacuum arc evaporation $[4,5]$. It is remarkable for a high deposition rate of synthesized coatings and an adequate plasma density near their surfaces. The performance of coated products can be improved using combined treatment, which includes preliminary strengthening of the product surface and deposition on the surface of the hard coating using the vacuum arc evaporation of a titanium target [6]. Drawbacks of the arc method are nonuniformity of the discharge plasma in the process chamber, as well as the soft metal droplets in the hard coatings. To prevent the droplets in the coatings, the vacuum arc plasma can be filtered [7].

\footnotetext{
* e-mail: a.metelestankin.ru
}

Another method widely used for the production of titanium vapor is magnetron sputtering [8], which excludes the metal droplets. However, the magnetron sputtering is characterized by a low efficiency of the target material use, a low ionization degree of sputtered atoms and a low plasma density near the product surface. In this case, the growing coatings should be bombarded by beams of fast neutral atoms [9-11].

Due to development of magnetrons with rotating cylindrical targets [12] efficiency of the target material use was improved. The density of magnetron discharge plasma near the product surface and the sputtering rate are substantially enhanced when a pulsed dc magnetron [13] is used. When high-power pulsed magnetrons [14] are used, the ionization degree of sputtered atoms grows up to 60 $80 \%$. With the use of unbalanced magnetrons [15-17], which ensure an adequate ion current density on the product surface, the plasma density near the negatively biased product grows by many times. A serious drawback of the magnetron method is a great reduction of the coating deposition rate, while using a reactive gas, for instance, nitrogen, to synthesize a titanium nitride coating. It is due to deposition on the target of chemical compounds, whose sputtering rate is much less compared to the pure metals.

The metal vapor can also be produced due to sputtering a target placed at the bottom of a hollow cathode [18-22] even without using the magnetic field to maintain the glow 
discharge at the low gas pressure. In the latter case the target sputtering rate and coating deposition rate both greatly decrease, when a reactive gas is added to argon. The reason is the same as in the above magnetron method.

The coating deposition rate is independent of the reactive gas only when the metal atoms are evaporated from the target surface, for instance by the cathode spots of the mentioned above vacuum arc. Another way to evaporate the target is heating with an intense electron beam [23]. There are no metal droplets in synthesized coatings in this case. However, an appreciable amount of the target material on its surface is liquid. For this reason, the products to be coated should be placed over the target. Negative biasing of the product allows bombardment of the growing coating by ions accelerated from the plasma produced by the electron beam. However, this plasma is also non-uniform, and its density is not enough for an adequate ion bombardment, the same as in the above conventional magnetron sputtering systems.

It was found in [24-26] that in the low-pressure glow discharge a small anode placed inside a large hollow cathode can be heated to the melting point of the anode material. The heating can be used for the metal vapor production and the coating deposition. However, this assumption has yet to be proved. The present work is devoted to the investigation of the coating deposition using titanium evaporation in a molybdenum crucible used as an anode of the low-pressure hollow-cathode glow discharge, when the process vacuum chamber is used as a hollow cathode.

\section{Experimental setup}

To carry out the investigations a $500-\mathrm{mm}$ diameter and 600-mm-long vacuum chamber was used (Fig. 1). The chamber inner volume amounts to $V=0.118 \mathrm{~m}^{3}$ and its inner surface area amounts to $S=1.46 \mathrm{~m}^{2}$. On the upper flange of chamber 1 is mounted high-voltage feedthrough 2 enabling immersion in gas-discharge plasma 3 of flat square anode 4 hanged up using a 1-mm-diameter molybdenum wire under the upper flange. The anode is made of 2-mmthick titanium sheet and its surface area $S_{a}$ is step-by-step diminished in successive experiments from $\sim 0.1$ to $\sim 0.001 \mathrm{~m}^{2}$.

On the bottom flange of the chamber is mounted another feedthrough 5 with vertical steel rod 6 and fastened to the rod 30-mm-long hollow anode 7 with the inner diameter of $12 \mathrm{~mm}$. Both the hollow anode and the rod are shielded by cylinder 8 with inner diameter of $30 \mathrm{~mm}$ connected to the grounded chamber. The upper end of the cylinder is $15 \mathrm{~mm}$ higher than the upper end of the hollow anode.

On the chamber wall is mounted third feedthrough 9 , which is used for immersion in plasma 3 of substrate holder 10 distant from hollow anode 7 at $100 \mathrm{~mm}$. The gas pressure in the chamber is measured by MKS-vacuummeter (USA) with transducer BARATRON in the pressure range $0.1-5 \mathrm{~Pa}$ and by VIT- 3 vacuummeter with the ion gauge PMI-2 in the pressure range $0.001-0.1 \mathrm{~Pa}$. The gas enters the chamber through connecting pipe 11 and is evacuated from the chamber through ground-

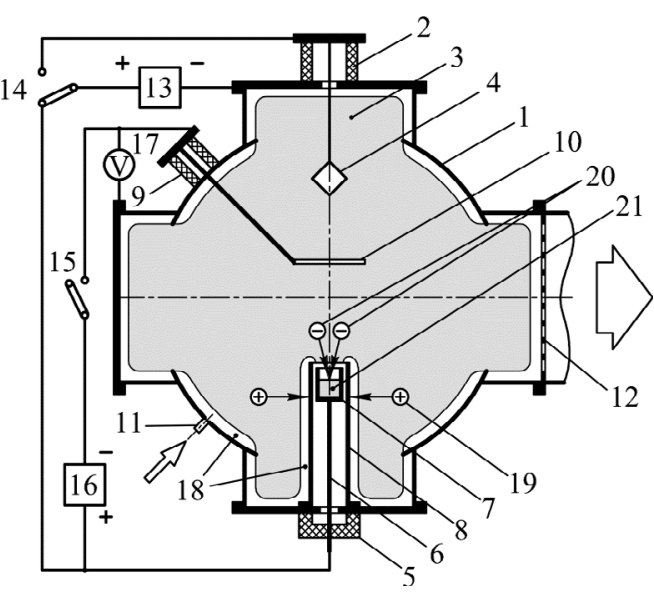

Fig. 1. Schematic diagram of the experimental setup (1) vacuum chamber; $(2,5,9)$ feedthrough; (3) plasma; (4) flat anode; (6) steel rod; (7) hollow anode; (8) grounded cylinder; (10) substrate holder; (11) connecting pipe; (12) grounded grid; $(13,16)$ DC power supplies; $(14,15)$ switches; $(17)$ voltmeter; $(18)$ cathode sheath; (19) ions; (20) electrons; (21) liquid titanium.

ed grid 12 by a turbo-molecular pump, which ensures the residual gas pressure of $0.001 \mathrm{~Pa}$. Using a gas supply system the pressure inside the chamber can be regulated from 0.001 to $5 \mathrm{~Pa}$. Negative pole of DC power supply 13 is connected to the grounded chamber and its positive pole can be connected using switch 14 to square anode 4 or hollow anode 7 . When switch 15 is closed, DC power supply 16 allows application of the negative bias voltage to substrate holder 10 . When switch 15 is open, electrostatic voltmeter 17 allows measurement of the floating holder potential, which is practically equal to the cathode fall of potential.

On the chamber door there is a 20 -mm-diameter quartz window (not shown in Fig. 1) used for remote temperature measurements of anode 4 and substrate holder 10 with pyrometer IMPAC IP 140 produced by the LumaSense Technologies GmbH (Germany).

\section{Experimental results}

When power supply 13 is connected to square anode 4 , switch 15 is open and the voltage between the anode and the chamber amounts to $1-1.5 \mathrm{kV}$, increase of the argon pressure up to $p \sim 0.5 \mathrm{~Pa}$ results in breakdown and ignition of the gas discharge. A stationary glow discharge is established with the discharge voltage $U \sim 400 \mathrm{~V}$, and the chamber is filled with a quite homogeneous bright glow of plasma 3 . The plasma is separated from the chamber walls, grid 12 and cylinder 8 with a cathode sheath 18 intensity of the glow in the sheath being less than in the plasma. The mean current density on the chamber walls at the maximal discharge current $I=2$ A amounts to $j=1.37 \mathrm{~A} \cdot \mathrm{m}^{-2}$, and at the minimal cathode fall of potential $U_{c} \approx 400 \mathrm{~V}$ the mean width of the cathode sheath according to the ChildLangmuir law amounts to $d=7.1 \mathrm{~mm}$. It exceeds diameters of the orifices in the grid 12 being equal to $5 \mathrm{~mm}$, and for 


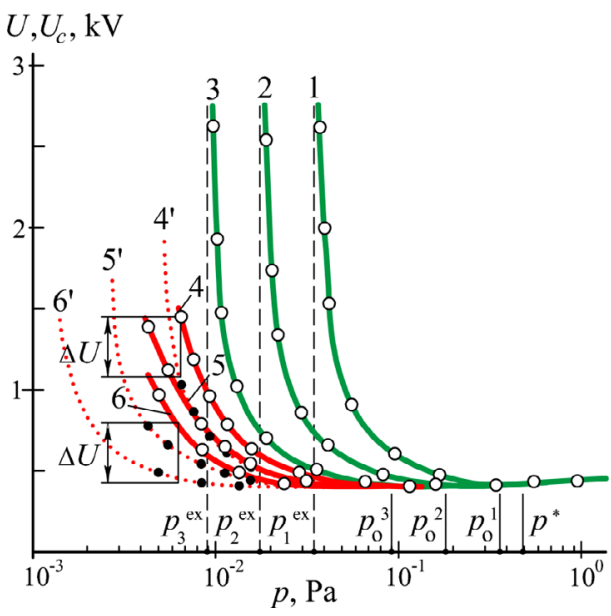

Fig. 2. Dependence of the discharge voltage $U$ (full curves) and the cathode potential fall $U_{\mathrm{c}}$ (dotted curves) on argon pressure $p$ at the current $I=0.5 \mathrm{~A}$ and anode surface area $S_{\mathrm{a}}=0.064$ (1), $0.032(2), 0.016(3), 0.008(4), 0.004(5)$ and $0.002 \mathrm{~m}^{2}(6)$. At $p<p_{\mathrm{o}}$ the voltage rises and at $p=p^{\text {ex }}$ the discharge extinguishes.

this reason the plasma does not penetrate into the pumping system in the whole range of parameters $I=0.2 \div 2 \mathrm{~A}$ and $U=0.4 \div 3 \mathrm{kV}$.

Prior to start measurements the chamber walls are bombarded during 30 minutes by $400-500-\mathrm{eV}$ argon ions from the plasma filling the chamber at the argon pressure $p=0.1 \mathrm{~Pa}$ and the discharge current of $2 \mathrm{~A}$. It is needed to reduce the percentage of impurities at low argon pressure.

Figure 2 presents dependencies of the discharge voltage $U$ between anode 4 and chamber 1 as well as the cathode fall of potential $U_{\mathrm{c}}$ measured between substrate holder 10 and the chamber with voltmeter 17 at the discharge current of $I=0.5 \mathrm{~A}$ in the anode circuit and various surface areas of the anode $S_{\mathrm{a}}$. They show that at $S_{\mathrm{a}} \geq 0.016 \mathrm{~m}^{2}$ the cathode fall of potential $U_{\mathrm{c}}$ is practically equal to the discharge voltage $U$, however at $S_{\mathrm{a}}=0.002$ $\div 0.008 \mathrm{~m}^{2} U$ substantially exceeds $U_{\mathrm{c}}$. When at $S_{\mathrm{a}}=$ $0.064 \mathrm{~m}^{2}$ the argon pressure is reduced from $p=1 \mathrm{~Pa}$ to $p^{*}=0.5 \mathrm{~Pa}$, the cathode fall $U_{\mathrm{c}}$ slightly decreases from $440 \mathrm{~V}$ to a minimal value of $405 \mathrm{~V}$ and keeps this value till $p$ reaches $p_{\mathrm{o}}{ }^{1}=0.37 \mathrm{~Pa}$ and starts rising with the further pressure reduction. At $S_{\mathrm{a}}=0.032 \mathrm{~m}^{2}$ the cathode fall $U_{\mathrm{c}}$ keeps the minimal value of $405 \mathrm{~V}$ till $p$ reaches $p_{\mathrm{o}}{ }^{2}=0.19$ $\mathrm{Pa}$ and then $U_{\mathrm{c}}$ starts rising with the further pressure reduction.

At $S_{\mathrm{a}}=0.016 \mathrm{~m}^{2}$ the cathode fall $U_{\mathrm{c}}$ starts rising with the further pressure reduction at $p_{\mathrm{o}}{ }^{3}=0.09 \mathrm{~Pa}$, at $S_{\mathrm{a}}=$ $0.008 \mathrm{~m}^{2} U_{\mathrm{c}}$ starts rising at $0.045 \mathrm{~Pa}$ (dotted curve $4^{\prime}$ in Fig. 2), at $S_{\mathrm{a}}=0.004 \mathrm{~m}^{2} U_{\mathrm{c}}$ starts rising at $0.022 \mathrm{~Pa}$ (dotted curve $5^{\prime}$ ) and at $S_{\mathrm{a}}=0.002 \mathrm{~m}^{2} U_{\mathrm{c}}$ starts rising at $0.011 \mathrm{~Pa}$ (dotted curve $5^{\prime}$ ). Comparison of the dotted curves $4^{\prime}, 5^{\prime}$ and $6^{\prime}$ of the cathode fall of potential $U_{\mathrm{c}}$ with full curves 4,5 and 6 of the discharge voltage $U$ reveals a positive anode fall of potential $\Delta U$ being equal to the potential difference $U-U_{\mathrm{c}}$ between the anode and the floating substrate holder. Figure 3 shows that with the pressure decrease from 0.4 to $0.01 \mathrm{~Pa}$ the anode fall of potential $\Delta U$ grows from $\sim 25$ to $\sim 500 \mathrm{~V}$ at the discharge current $I=0.7 \mathrm{~A}$.

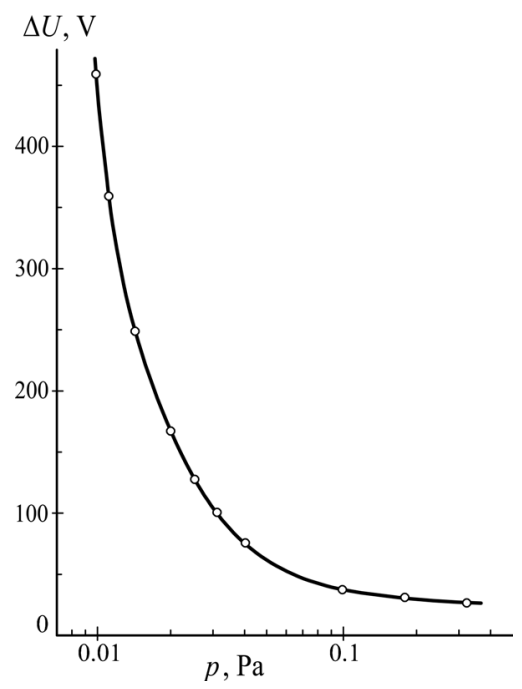

Fig. 3. Dependence of the positive anode fall of potential $\Delta U$ on the gas pressure $p$ at the discharge current $0.7 \mathrm{~A}$ and the anode surface area $S_{\mathrm{a}}=0.002 \mathrm{~m}^{2}$.

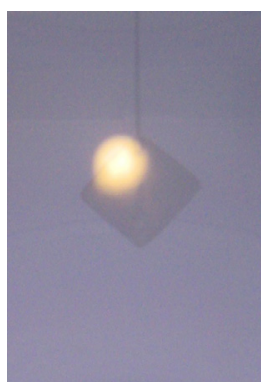

a

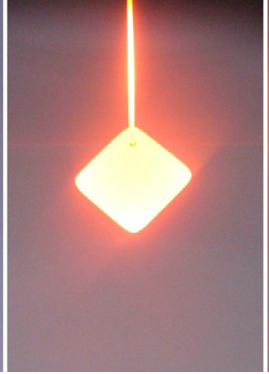

b

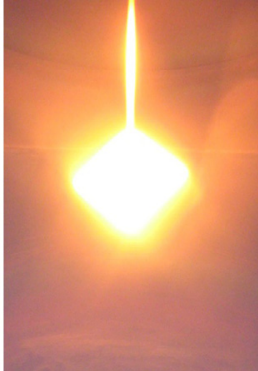

Fig. 4. Photographs of the anode with $S_{\mathrm{a}}=0.002 \mathrm{~m}^{2}$ at the discharge current $\mathrm{I}=0.7 \mathrm{~A}$ and argon pressure $\mathrm{p}=0.4$ (a), 0.015 (b) and $0.008 \mathrm{~Pa}(\mathrm{c})$.

Figure 4 shows the anode with the surface area $S_{\mathrm{a}}=0.002 \mathrm{~m}^{2}$ at the same discharge current $I=0.7 \mathrm{~A}$ and different argon pressures. At the pressure of $p=0.4 \mathrm{~Pa}$ the positive anode fall of potential amounts to $\Delta U \sim 25 \mathrm{~V}$ and is characterized with a bright ball of plasma near the anode surface (Fig. 4a). In contrast to the pale blue color of the homogeneous plasma filling the chamber, the anode plasma ball is yellow. Measurement with the pyrometer showed that the anode temperature in this case amounts to $250^{\circ} \mathrm{C}$.

With the pressure reduction the anode plasma ball grows in size and its yellow color turns to violet. Finally the anode plasma disappears, the anode fall of potential $\Delta U$ and the anode temperature $T$ start to grow rapidly. At $\mathrm{p}=0.015 \mathrm{~Pa}$, the anode fall of potential amounts to $\Delta U=250 \mathrm{~V}$, measured with pyrometer temperature amounts to $T=1050{ }^{\circ} \mathrm{C}$ (Fig. $4 \mathrm{~b}$ ). At $\mathrm{p}=0.008 \mathrm{~Pa}$, the anode fall reaches $\Delta U=600 \mathrm{~V}$ and the titanium anode starts melting (Fig. 4c).

When power supply 13 is connected to hollow molybdenum anode 7 , the effective anode surface area $S_{\mathrm{a}}<0.0007 \mathrm{~m}^{2}$, which is 3 times less than in the case of the flat anode presented in Figure 4. For this reason at the 


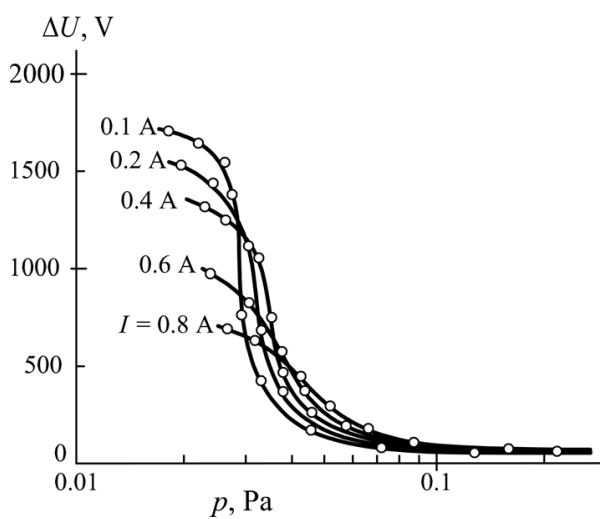

Fig. 5. Dependence of the anode fall of potential $\Delta U$ on the nitrogen pressure $p$ at the discharge current $I=0.1 \div 0.8 \mathrm{~A}$ and the hollow anode filled with titanium.

same discharge currents $I$ the positive anode fall of potential can reach with decreasing the gas pressure $\Delta U \sim 2000 \mathrm{~V}$ in argon and $\Delta U \sim 1700 \mathrm{~V}$ in nitrogen. At the gas pressure $p \sim 0.1 \mathrm{~Pa}$, a bright ball of the anode plasma is observed in the opening of grounded cylinder 8 (Fig. 1). With the pressure decreasing the plasma ball grows in size, turns its yellow color to violet and disappears at $p \sim 0.03$ $\mathrm{Pa}$, the same as in the case of flat anode 4.

After the decay of the anode plasma, the anode fall of potential abruptly rises from $\Delta U \sim 300 \mathrm{~V}$ to $\Delta U \sim 1500 \mathrm{~V}$ and higher. If the molybdenum hollow anode is previously filled with small titanium cheeps, heating of the cheeps by accelerated electrons 20 results in the titanium melting and the production of the titanium vapor flow from the surface of liquid titanium 21 to substrate holder 10. The experimental curves presented in Figure 5 show that the anode fall of potential starts to rise at higher pressure with increasing the discharge current.

After the anode fall of potential $\Delta U$ reaches a certain value $\Delta U^{*}$, it suddenly falls down to $\Delta U \sim 100 \mathrm{~V}$, then grows to the previously reached value of $\Delta U^{*}$ and falls down again. In this case oscillations of the discharge voltage $U$ and anode fall of potential $\Delta U$ take place their frequency amounting to $0.2-0.4 \mathrm{~Hz}$.

The maximal experimentally achieved value of the anode fall of potential $\Delta U^{*}$ is decreasing with increasing of the discharge current. Plasma 3 is separated from cylinder 8 by positive space charge sheath of ions 19 and from the anode 7 by negative space charge sheath of electrons 20 inside the cylinder.

Electrical power of the anode heating by electrons is equal to $P=I \times \Delta U^{*}$ and with increasing of the discharge current $I$ rises from $170 \mathrm{~W}$ at $I=0.1 \mathrm{~A}$ to $550 \mathrm{~W}$ at $I=0.8 \mathrm{~A}$ (Fig. 6). At the discharge current $I>0.4 \mathrm{~A}$ electrons accelerated in the negative space charge sheath transport into the crucible with the inner diameter of $12 \mathrm{~mm}$ about the same electrical power of $P \sim 0.55 \mathrm{~kW}$. It means that the power density on the liquid titanium surface of $1.13 \mathrm{~cm}^{2}$ amounts to $\sim 5 \times 10^{6} \mathrm{~W} \cdot \mathrm{m}^{-2}$, which is quite enough for titanium evaporation and synthesis of titanium nitride coatings on the substrate.

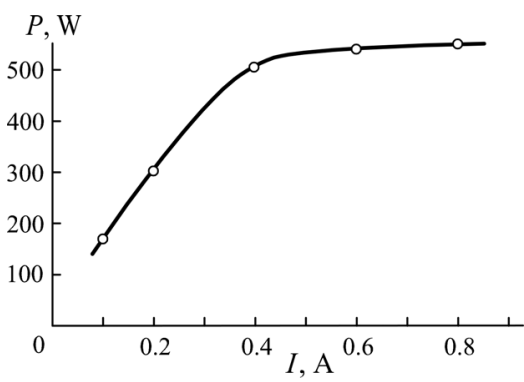

Fig. 6. Dependence of the electrical power $P$ heating the hollow anode on the discharge current $I$.

A HSS substrate with a mask on its polished surface was fastened under substrate holder 10. Before the coating deposition the substrate and the mask were cleaned and heated by argon ions. To carry out the cleaning, chamber 1 is filled with argon and switch 15 is closed. At the discharge current of $2 \mathrm{~A}$ and the argon pressure of $0.5 \mathrm{~Pa}$ the anode fall $\Delta U$ does not exceed $50 \mathrm{~V}$ and heating of the titanium inside the hollow anode is negligible. In this case application to the substrate holder of the negative bias voltage $\sim 900 \mathrm{~V}$ from power supply 16 (Fig. 1) results in the bombardment of the substrate by argon ions with energy $\sim 1000 \mathrm{eV}$, which effectively clean and heat it.

After the 10-min-long pre-treatment argon is replaced with nitrogen. At the gas pressure of $0.025 \mathrm{~Pa}$ and the discharge current of $0.6 \mathrm{~A}$ the anode fall of potential amounts to $\Delta U=900 \mathrm{~V}$, and on the substrate bombarded by $100-\mathrm{eV}$ nitrogen ions during 1-hr is synthesized titanium nitride coating. To ensure the ion energy value of $100 \mathrm{eV}$, readings of voltmeter 17 at open switch 15 exceed by $100 \mathrm{~V}$ readings of this voltmeter at closed switch 15 and the bias voltage applied to the substrate from power supply 16 .

After the coating deposition, the mask is removed from the substrate surface, and the height $\delta$ of the step between covered by the mask and open surfaces of the substrate is measured using stylus profiler DectakXT produced by Bruker Nano, Inc. (USA). It amounts to $4.9 \mu \mathrm{m}$ and the coating deposition rate is equal to $\sim 5 \mu \mathrm{m} \cdot \mathrm{h}^{-1}$. The coating color is gold, and using X-ray diffractometer EMPYREAN produced by PANALYTICAL (Netherlands) it was found that the coating contains only one phase of TiN. After the nitrogen is replaced with argon, titanium coating is deposited, and the deposition rate amounts to about the same value of $5 \mu \mathrm{m} \cdot \mathrm{h}^{-1}$.

\section{Discussion}

It was found in [28] that decreasing losses of fast electrons from a hollow cathode and increasing the cathode sizes it is possible to reduce operating pressure of the hollow-cathode glow discharge by two orders of magnitude down to $\sim 0.01 \mathrm{~Pa}$. This finding greatly enlarged technological capabilities of the glow discharge, and it was already used for the processing of machine parts and cutting tools by the broad beams of accelerated electrons, ions and fast neutral atoms, as well as for the plasma immersion ion implantation. 
When a vacuum process chamber is used as a big hollow cathode, the gas is ionized by electrons emitted by the chamber walls and fast electrons produced in the cathode sheath near the chamber surface [28]. Length of the way $L=4 \mathrm{~V} / S_{\text {a }}$, here $V$ is the chamber volume and $S_{\text {a }}$ is the anode surface area, which those electrons repelled from the chamber walls hundreds of times pass before reaching the anode, exceeds the chamber width $a$ hundreds of times.

Oscillating inside the chamber electrons visit all the parts of the chamber volume on their way to the anode. Hence, inside the chamber, which plays the role of an electrostatic trap for the electrons, probability of the gas ionization by those electrons is distributed uniformly.

At a high anode surface area $S_{\mathrm{a}}$ the cathode fall of potential $U_{\mathrm{c}}$ is equal to the discharge voltage $U$. At a constant discharge current, it is independent of the pressure in the range from $p_{\mathrm{o}}$ to $p^{*}$. The upper limit $p^{*}$ of this pressure range meets equation $\lambda_{N}(p)=a$, here $a=4 V / S$ is the chamber width, $S$ is the surface area of its inner walls and $\lambda_{N}(p)$ is the mean pass of emitted by the chamber electrons with initial energy $e U_{\mathrm{c}}$ between ionizing collisions at the gas pressure $p$. The lower limit $p_{\mathrm{o}}$ of the above pressure range meets equation $L=\Lambda(p) \equiv\left(e U_{\mathrm{c}} / W\right) \lambda_{N}(p)$, here $W$ is the ionization cost, and $\Lambda(p)$ is the mean way, which the electrons have to pass at the gas pressure $p$ in order to spend all their initial energy $e U_{\mathrm{c}}$ on the gas ionization. The lower limit $p_{\mathrm{o}}$ decreases proportionally to $S_{\mathrm{a}}$.

In the above pressure range the mean pass $\lambda_{N}$ of emitted by the chamber electrons between ionizing collisions exceeds the trap width $a$, and the trap length $L$ exceeds the energy relaxation length $\Lambda$ of those electrons. In these conditions electrons spend all their initial energy on the gas ionization, and contribution to the gas ionization of fast electrons produced in the cathode sheath is independent of the pressure and determined only by the ratio $d / a$ of the cathode sheath width $d$ to the chamber width $a$. When the discharge current grows up, the sheath width and contribution to the gas ionization of electrons produced in the sheath both decrease.

At $p<p_{\mathrm{o}}$ the length $\Lambda$ exceeds the mean way $L$ of electrons emitted by the chamber to the anode, they spend only a part of their energy on the gas ionization and heat the anode with the rest of their energy. For keeping the discharge current with the pressure decreasing the contribution of fast electrons produced in the cathode sheath should be increased, and for this purpose the ratio $d / a$ should be raised. In accordance with the ChildLangmuir law [29] the cathode sheath width $d$ is proportional to $U_{\mathrm{c}}^{3 / 4}$, and for this reason at $\Lambda>L$ the discharge voltage $U=U_{c}$ abruptly rises, when the pressure is decreasing from $p_{\mathrm{o}}$ to the pressure $p^{\text {ex }}$ of the discharge extinguishing (full curves 1-3 in Fig. 2).

When the anode surface $S_{\mathrm{a}}$ is less than a critical value $S_{\mathrm{a}}{ }^{*}=(2 m / M)^{1 / 2} S$, here $m$ and $M$ are the electron mass and the ion mass and $S$ is the surface area of the chamber walls, the positive anode fall of potential $\Delta U$ appears [30]. In this case the discharge voltage amounts to $U=U_{c}+\Delta U$ (full curves 46 in Fig. 2) and substantially exceeds the cathode fall of potential $U_{c}$ (dotted curves $4-6$ in Fig. 2). At the gas pressure $p>0.1 \mathrm{~Pa}$ the anode fall of potential $\Delta U$ does not exceed $100 \mathrm{~V}$ and is concentrated between the discharge plasma filling the chamber and the plasma ball near the anode surface (Fig. 4a). After the decay of the plasma ball $\Delta U$ grows by an order of magnitude and is concentrated immediately between the discharge plasma and the anode. In the latter case all electrons produced in the discharge are accelerated by the anode fall of potential $\Delta U$ and spend all their energy on the anode heating (Fig. 4b) and melting (Fig. 4c).

At a constant discharge current the anode fall of potential $\Delta U$ and the electrical power heating the liquid titanium in the molybdenum anode-crucible increase with the gas pressure decreasing. It results in growth of the titanium vapor pressure near the anode and a decrease of $\Delta U$. Reduction of the heating power leads to a decrease of the liquid titanium temperature and the titanium vapor pressure. It results in growth of $\Delta U$, the titanium pressure rises again, and so on. To exclude these oscillations the growth of $\Delta U$ should be limited with a certain value of $\Delta U^{*}$. It turned out that a stable evaporation of titanium in the molybdenum anode-crucible can occur at the electrical power heating the anode not exceeding $\sim 0.55 \mathrm{~kW}$ (Fig. 6 ), which corresponds to the mean power density not exceeding $\sim 5 \times 10^{6} \mathrm{~W} \cdot \mathrm{m}^{-2}$.

In order to raise the flow of titanium atoms from the crucible to the products under processing it is needed to increase the surface of evaporating liquid metal. In our case the positive anode fall of potential $\Delta U$ also takes place at the anode surface area $S_{\mathrm{a}}=80 \mathrm{~cm}^{2}$, which is about 40 times higher than the effective surface $\sim 2 \mathrm{~cm}^{2}$ of the anode-crucible with outer diameter of $1.6 \mathrm{~cm}$. It seems that an increase in the anode-crucible diameter up to $4 \mathrm{~cm}$ could heighten the evaporating surface of the liquid titanium and the flow of the titanium atoms by 6 times at the same mean value $\sim 500 \mathrm{~W} \cdot \mathrm{cm}^{-2}$ of the heating power density and the total heating power of $3-4 \mathrm{~kW}$.

\section{Conclusions}

- The titanium evaporation in the anode-crucible by electrons accelerated from the glow discharge plasma allows synthesis in the same plasma of the titanium nitride coatings not containing the titanium droplets, which enables an appreciable improvement of the machine parts and the cutting tools quality.

- In the glow discharge with a process vacuum chamber used as a hollow cathode at the anode-crucible surface less than a critical value $S^{*}=(2 m / M)^{1 / 2} S$, where $S$ is the inner surface area of the chamber, $m$ is the mass of electrons and $M$ is the mass of ions, the positive anode fall of potential appears and grows up to $1.5-2 \mathrm{kV}$ with the pressure decreasing, which allows to heat and melt titanium in the crucible by accelerated electrons.

- The power density of electrons heating the liquid titanium is limited by the metal vapor pressure near the anode and does not exceed $0.5 \mathrm{~kW} \cdot \mathrm{cm}^{-2}$. In order to increase the flow of titanium atoms to the products under processing it is needed to heighten the crucible diameter.

Acknowledgements. This work was financially supported by the Ministry of Education and Science of Russian Federation in the framework of the state task in the field of scientific activity of MSTU "STANKIN" No 9.1372.2017/4.6. 
The work was carried out using the equipment of the Center of collective use of MSTU "STANKIN".

\section{References}

[1] R.L. Boxman, V.N. Zhitomirsky, Vacuum arc deposition devices, Rev. Sci. Instrum. 77 (2006) 021101, DOI: 10.1063/1.2169539

[2] S. Grigoriev, A. Metel, Plasma- and beam-assisted deposition methods, in: A.A. Voevodin, D.V. Shtansky, E.A. Levashov, J.J. Moore (Eds.) Nanostructured thin films and nanodispersion strengthened coatings. Kluwer Academic Publishers, Boston, Dordrecht, London, 2004, pp. 147-154, DOI: $10.1007 / 1-4020-2222-0 \_14$

[3] A.S. Metel, S.N. Grigoriev, Ȳu. A. Melnik, V.P. Bolbukov, Broad beam sources of fast molecules with segmented cold cathodes and emissive grids, Instrum. exp. tech. 55 (2012) 122-130, DOI: 10.1134/S0020441211060170

[4] I. Beilis, Y. Koulik, Y. Yankelevich, D. Arbilly, R. Boxman, Thin-film deposition with refractory materials using a vacuum arc, IEEE Trans. Plasma Sci. 43 (2015) 23232328, DOI: $10.1109 /$ TPS.2015.2432577

[5] K. Tanaka, A. Anders, Temporal evolution of ion energy distribution functions and ion charge states of $\mathrm{Cr}$ and $\mathrm{Cr}-\mathrm{Al}$ pulsed arc plasmas, J. Vac. Sci. Technol. A 323 (2015) 061301, DOI: 10.1116/1.4926750

[6] S.N. Grigoriev, A.S. Metel, S.V. Fedorov, Modification of the structure and properties of high-speed steel by combined vacuum-plasma treatment, Metal Sci. Heat Treatment 54 (2012) 8-12, DOI: 10.1007/s11041-012-9447-x

[7] R.L. Boxman, V.N. Zhitomirsky, B. Alterkop, E. Gidalevich, I. Beilis, M. Keidar, S. Goldsmith, Recent progress in filtered vacuum arc deposition, Surf. Coat. Technol. 86-87 (1996) 243-253, DOI: 10.1016/s0257-8972(96)03023-x

[8] J. Musil, A. Rajský, A.J. Bell, J. Matouš, M. Čepera, J. Zeman, High-rate magnetron sputtering, J. Vac. Sci. Technol. A 14 (1996) 2187-2191, DOI: 10.1116/1.580045

[9] S.N. Grigoriev, Yu. A. Melnik, A.S. Metel, M.A. Volosova, Focused beams of fast neutral atoms in glow discharge plasma, J. Appl. Phys. 121 (2017) 223302, DOI: 10.1063/1.4985249

[10] A. Metel, M. Volosova, S. Grigoriev, Yu. Melnik, Products pre-treatment and beam-assisted deposition of magnetron sputtered coatings using a closed cylindrical grid inside a planetary rotation system, Surf. Coat. Technol. 325 (2017) 327-332, DOI: 10.1016/j.surfcoat.2017.06.071

[11] S. Veprek, H.-D. Mannling, P. Karvankova, J. Prochazka, The issue of the reproducibility of deposition of superhard nanocomposites with hardness of $\geq 50 \mathrm{GPa}$, Surf. Coat. Technol. 200 (2006) 3876-3885, DOI: 10.1016/j.surfcoat.2004.11.023

[12] H.E. McKelvey, Magnetron cathode sputtering apparatus. US Patent No 4, 356, 073, 1982

[13] J. Musil, J. Leština, J. Vlček, T. Tölg, Pulsed dc magnetron discharge for high-rate sputtering of thin films, J. Vac. Sci. Technol. A 19 (2001) 420-424, DOI: 10.1116/1.1339018

[14] A. Anders, Tutorial: Reactive high power impulse magnetron sputtering, J. Appl. Phys. 121 (2017) 171101, DOI: $10.1063 / 1.4978350$

[15] R.P. Howson, H.A. Jafer, A.G. Spencer, Substrate effects from an unbalanced magnetron, Thin Solid Films 193/194 (1990) 127-137, DOI: 10.1016/s0040-6090(05)80020-3
[16] S. Kadlec, J. Musil, W.-D. Münz, G. Hakansson, J. Sundgren, Reactive deposition of TiN films using an unbalanced magnetron, Surf. Coat. Technol. 39/40 (1989) 487-497, DOI: $10.1016 /$ S0257-8972(89)80010-6

[17] W.-D. Münz, D. Schulze, F.J.M. Hauzer, A new method for hard coatings: $\mathrm{ABS}^{\mathrm{TM}}$ (arc bond sputtering), Surf. Coat. Technol. 50 (1992) 169-178, DOI: 10.1016/0257-8972(92)90058-I

[18] S.N. Grigoriev, Yu.A. Melnik, A.S. Metel, V.V. Panin, V.V. Prudnikov, A compact vapor source of conductive target material sputtered by $3-\mathrm{keV}$ ions at $0.05-\mathrm{Pa}$ pressure, Instrum. Exp. Tech. 52 (2009) 731-737, DOI: 10.1134/ S0020441209050170

[19] A. Metel, V. Bolbukov, M. Volosova, S. Grigoriev, Yu. Melnik, Source of metal atoms and fast gas molecules for coating deposition on complex shaped dielectric products, Surf. Coat. Technol. 225 (2013) 34-39, DOI: 10.1016/j.surfcoat.2013.03.013

[20] A.S. Metel, S.N. Grigoriev, M.A. Volosova, Yu.A. Melnik, Magnetron sputtering device with generation of pulsed beams of high-energy gas atoms, Instrum. Exp. Tech. 60 (2017) 290-296, DOI: 10.1134/S0020441217020117

[21] S.N. Grigoriev, A.S. Metel, M.A. Volosova, Yu.A. Melnik, Surface hardening by means of plasma immersion ion implantation and nitriding in glow discharge with electrostatic confinement of electrons, Mechanics \& Industry 16 (2015) 711, DOI: $10.1051 / \mathrm{meca} / 2015093$

[22] S.N. Grigoriev, A.S. Metel, M.A. Volosova, Yu.A. Melnik, Deposition of wear-resistant coatings using a combined source of metal atoms and fast gas molecules, Mechanics \& Industry 16 (2015) 705, DOI: 10.1051/meca/2015092

[23] R. Ramaseshan, F. Jose, S. Rajagopalan, S. Dash, Preferentially oriented electron beam deposited TiN thin films using focused jet of nitrogen gas, Surf. Eng. 32 (2016) 834-839, DOI: $10.1080 / 02670844.2016 .1159832$

[24] A.S. Metel, S.N. Grigoriev, Yu.A. Melnik, V.V. Panin, Filling the vacuum chamber of a technological system with homogeneous plasma using a stationary glow discharge, Plasma Phys. Rep. 35 (2009) 1058-1067 DOI: 10.1134/ s1063780x09120095

[25] A.S. Metel, S.N. Grigoriev, M.A. Volosova, V.P. Bolbukov, Yu.A. Melnik, Role of electrostatic and magnetic electron confinement in a hollow-cathode glow discharge in a nonuniform magnetic field, Plasma Phys. Rep. 41 (2015) 188-197 DOI: 10.1134/S1063780X14120058

[26] A. Metel, V. Bolbukov, M. Volosova, S. Grigoriev, Yu. Melnik, Equipment for deposition of thin metallic films bombarded by fast argon atoms, Instrum. Exp. Tech. 57 (2014) 345-351, DOI: 10.1134/S0020441214020110

[27] I. Smurov, M. Doubenskaia, S. Grigoriev, A. Nazarov, Optical Monitoring in Laser Cladding of Ti6Al4V, J. Therm. Spray Technol. 21 (2012) 1357-1362

[28] A.S. Metel, Effect of ionization in the cathode layer on the characteristics of a Penning discharge. I. Hollow cathode discharge, Sov. Phys. Tech. Phys. 30 (1985) 1133-1136

[29] I. Langmuir, The interaction of electron and positive ion space charges in cathode sheaths, Phys. Rev. 33 (1929) 954989, DOI: 10.1103/PhysRev.33.954

[30] V.I. Kolobov, A.S. Metel, Glow discharges with electrostatic confinement of fast electrons, J. Phys. D: Appl. Phys. 48 (2015) 233001, DOI: 10.1088/0022-3727/48/23/233001

Cite this article as: S.N. Grigoriev, Y.A. Melnik, A.S. Metel, M.A. Volosova, A new method for production of titanium vapor and synthesis of titanium nitride coatings, Mechanics \& Industry 18, 709 (2017) 